\author{
SungWon Hwang, Wolff-Michael Roth, \& Lilian Pozzer-Ardenghi
}

\title{
Understanding Collaborative Practice: Reading between the Lines Actions
}

\section{Summary}

Collaboration is the central aspect of human practice; without it and the associated division of labor human society as we know it today would not exist. Successful collaboration enables a collective subject to produce more than the sum of what its members can do individually. But which conditions enable successful collaboration and how does it come about? In a case study of artifact designing in a class of sixth- and seventh-grade students, we articulate how the social interaction produces and reproduces the prerequisite and required intersubjectivity for successful collaboration and thereby constitutes a configuration of successful collaboration at two dominant modes of design practice. In face-to-face communication, human bodies produce a variation of available social and material resources and thereby concretely realize the generalized possibilities of making individual subjectivity available to others. This, we show, produces and reproduces intersubjectivity. During cooperative action, human bodies take up different parts of the collective labor and thereby achieve a division of labor, but the different contributions are accomplished into a collective one through human bodies in action, which constitutes a form of communication. We conclude that evaluating collaboration requires reading the productive value from communication and the communicative value from the division of labor, which, in dialectical unfolding of collaborative interactions, articulates itself in and as of creating new action possibilities (room to maneuver) through acting human bodies and therefore requires reading between the actions.

Collaboration is the central aspect of human practice, which has enabled learning and development of human beings; without it and the associated division of labor there would not be human culture in the way we know it today. In human practice, a collective object emerges and develops through social interactions of individual subjects, of which the result is more than the sum of individual actions. Even in the case of animals (e.g., bees), simple individual actions ultimately contribute to producing a complex structure (e.g., a beehive); however, animals do not act upon conscious choices but implement division of labor in response to environmental conditions (Holzkamp, 1983). In humans, however, the division of labor is not only conscious but also leads to the possibility to choose among different forms of participation to sustain society and, in exchange of material goods and labor, still achieve the benefits that stem from collective activity. Notable in human collaboration, which distinguishes it from animal collaboration, is the complex process of inter-individual communication (Leont'ev, 1981). That is, collaborative practice involves not only cooperative but also communicative actions toward a collective object. What then constitutes successful collaboration or less successful collaboration? How can we properly understand, theorize, and evaluate collaborative practice?

Concerning the collaborative features of human practice and learning, quite a number of social studies have provided cultural and historical analyses of their mechanisms, how individual actions engage with one another (social interaction) and thereby constitute a dynamic configuration of collaboration (e.g., "zone of proximal development" [Vygotsky, 1978]). Among them, studies in cultural historical activity theory expanded the notion of the socially mediated action of Vygotsky to the activity system and elaborated the developmental aspects of collective activity from its object-orientedness (Engeström, 1987), that is, the productive value of collaboration. Although some activity-theoretic studies pointed out the importance and the communicative value 
of collaboration as an inseparable part of production in relation to the materiality of object and environment (e.g., Lektorsky, 1999), the communicative aspect of collaboration seems to have been more successfully studied in the ethnomethodological tradition. The discipline and method of conversation analysis (Sten Have, 1999), for example, has developed linguistic approaches to social interactions occurring in human subjects' everyday life (e.g., "talk-in-interaction" [Schegloff, 1996]). There has been a growing body of research attempting to deepen our understanding of the social dimension of collaborative production (e.g., Heath \& Hindmarsh, 2000; Hyysalo, 2002), but little work has been devoted to the mechanism of collaboration such as how social interactions come to construct the sociomaterial reality that is both objective and subjective (e.g., Berger \& Luckmann, 1966).

The purpose of this study is to uncover the essential but rarely articulated dimension of collaboration from a dialectical perspective on individuals and collective. We first describe details of the research design and context of the study from which our case materials were culled. Then we elaborate our initial research questions and embedded theoretical notions with a concrete case of artifact designing and proceed to articulate the results of our study summarized in the form of two major claims.

\section{Ethnographic Context}

This study is part of a research project in which researchers participate in designing school curricular activities and improving schooling through its integration with research practice ("design experiments" [Brown, 1992]). The project was conducted in a split sixth- and seventh-grade classroom, with ten students at the lower grade level ( 5 boys, 5 girls) and sixteen students at the upper grade level ( 7 boys, 9 girls). For most students, English was the first language, but six students were from different ethnic background and spoke a language other than English as their mother tongue. Two teachers co-taught the class. The regular homeroom teacher largely took responsibility for disciplinary and organizational issues; one of the authors planned the curriculum, conducted whole-class discussions, and advised students on conceptual issues related to sim- ple machines such as levers, pulleys, cranks, inclined planes, and elastics and springs and their advantages.

The Simple Machines Curriculum was designed to provide students with opportunities to learn science through being engaged in direct and relevant experiences of designing and building machines. Consequently, students spent 60 percent of this 36-lesson unit on designing, building, and presenting machines. The remainder was spent on hands-on activities specifically designed to give students exposure to the standard discourse of physics concerning simple machines ( 25 percent), and whole-class discussions that focused on forces, energy, and design of simple machines (15 percent). All activities therefore provided opportunities for students to do and talk physics and engineering design.

Over the course of the unit, students designed four hand-powered machines. The design activities were written in the form of requests for proposals - by the fictional company Northern Explorations Limited-for specialized, hand-operated machines that could be used when there were power failure blackouts (such as the cases that hit the northeastern US and Italy in the fall of 2003). The first three machines were designed to lift loads, move loads over a long distance, and move loads by means of a self-propelling mechanism. In their fourth and final design project, students were asked to combine a minimum of four processes, two of which had to be based on the simple machines discussed in the unit.

Three research team members collected data in an ongoing manner. All lessons were continuously recorded using two cameras. During whole-class activities, the second camera served as a backup to record students' talk as completely as possible. In addition, two audiotape recorders captured (a) students' talk during presentations, (b) teacher-student interactions, and (c) interviews conducted by a research assistant in the setting as students 
worked on their design projects. We collected students' notes containing their paper-and-pencil designs, photographs of the artifacts that they had produced, and glossary entries students constructed of their own choice for some key words used during the design activities. In addition to the taped records, ethnographic observations were documented in fieldnotes and in photographs. The teacher-researcher (WMR) was debriefed after each lesson; these debriefing sessions were documented in fieldnotes. The planned curriculum, all curricular materials, and the artifacts used during teaching became part of the database. All curriculum planning meetings and interviews were recorded.

Three authors viewed the videotapes repeatedly, both individually and collectively, with the intent to develop better understandings of the collaborative design processes. Our analysis was informed by the method of interaction analysis (Jordan \& Henderson, 1995), whereby researchers interact with one another to analyze interactions recorded on videotapes. In our individual and collective analysis sessions, we formed initial hypotheses that we sought to confirm or disconfirm in subsequent analyses or by running them by one another. Our results emerged from repeated cycles of generating, refining, accepting, disconfirming, or discarding working hypotheses. In the process, we generated written analyses of different episodes across the database.

From all recorded designing sessions, we ultimately selected two exemplary groups, two seventh-grade girls working with a sixth-grade girl (Bella, Leanne, \& Amy) and two sixthgrade boys and one seventh-grade girl (Dave, Jon, \& Maryam) for in-depth analysis. We analyzed the data sources by moving image by image through the design activity and transcribed the events. The large database of both groups afforded a number of episodes from which the prevalence of our theoretical claims came out. Therefore, the particular episodes that we selected as typical cases of collaboration are a matter of our pragmatic choice among many possible alternative episodes.

\section{Collaborative Practice: Production and Reproduction of Intersubjectivity}

We are in the science classroom where the sixth- and seventh-grade students learn about simple machines such as pulleys, levers, cranks, and inclined planes - the cultural devices that can provide a mechanical advantage when heavy loads are to be moved. In response to a request for proposals published by a fictional company, the students are working in groups on designing machines-we understand designing as comprising all steps from initial fleeting ideas over pencil drawings to the building and refining of prototype artifacts. The following episode ${ }^{1}$ occurred near the end of the four-month unit, while a group of three girls was working on a, the unit culminating capstone project in which four simple machines were combined into a bigger, Rube Goldberg machine. ${ }^{2}$

1 We used the following transcription conventions:

* Denotes the moment that corresponds to the video off prints [Figure], which we put in series to provide the data set of changing action. Each figure constitutes independent data that cannot be substituted by written descriptions;

(()) Salient and relevant actions are noted and are enclosed in double parentheses;

[ Square brackets in consecutive lines indicate the beginning of overlapping speech or action;

(?) Question mark in parentheses indicates inaudible utterance(s);

- Hyphen at the end of a word marks sudden stop of talk;

$\uparrow$ The arrow indicates a rise in intonation sharper and more clearly noticeable than normally occurs;

.; Punctuation marks are used to indicate characteristics of speech production rather than grammatical units.

2 Rube Goldberg designed cartoons in which people accomplished very simple things by means of very complicated machinery, deriving from the chaining of many very simple processes and machines. 


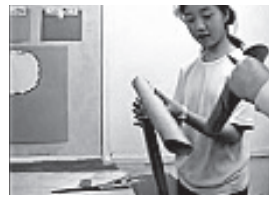

(a)

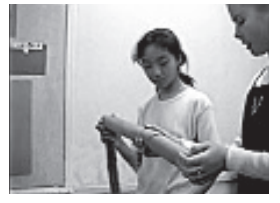

(b)

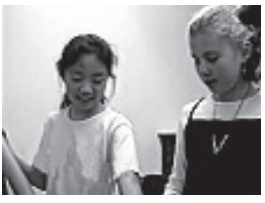

(c)

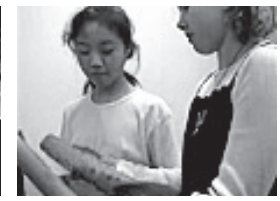

(d)

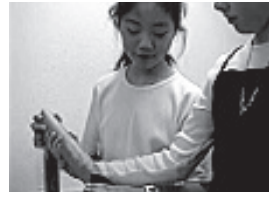

(e)

Figure 1 Bella and Leanne are in the process of deciding where and how to connect paper tubes of different length. a. Bella is putting one paper tube on top of the wooden board. b. Leanne is putting a shorter tube into the end of the longer one and suggesting gluing the two tubes. c. Bella's hand is moving between the floor and the end of the tube. d. Leanne is replacing the connected longer tube with the short tube that she put. e. Bella is pointing to the joint.

Episode 1 Bella and Leanne, who work in the same group, are designing their Rube Goldberg machine. Bella *is putting one paper tube on top of the wooden board, and Leanne is cutting another paper tube with scissors. After cutting, Leanne inserts one small tube into the end of the tube that Bella is holding. *[Figure 1a]

01 Leanne: Now we have to glue this $\left[_{1}^{*}\right.$ together. *[Figure $1 b]$

$\left[_{1}((\right.$ Leanne is putting one tube into the end of another and suggesting gluing the two tubes.))

02 Bella: Why?

03 Leanne: Because we want it long, I want it long.

04 Bella: But it will hit the floor. ((Bella and Leanne wrestle for the roll.)) Hold on, hold on it will hit this floor, but then we have to get $\left[_{2} *\right.$ the other part. *[Figure 1c]

$\left[_{2}\right.$ ((Bella's left hand moves out and continues moving further to the left. Her gaze moves up to look at Leanne.))

05 Leanne: $\left[{ }_{3}\right.$ Well then just use this *chute. *[Figure 1d]

$\left[_{3}\right.$ ((Leanne pulls out the short tube that she had previously inserted into the first one and uses it to replace the original one.))

06 Bella: Yeah, and then put a *board here. *[Figure 1e]

07 Leanne We actually $\left[_{4}\right.$ have to nail on it. Glue it on, try gluing first.

$\mathrm{C}_{4}$ ((Leanne's right hand moves forward to the top where the tube and the board join, then moves her index finger on the edge of the tube.))
Bella initially held a piece of paper tube to a wooden board (Figure 1a). As Leanne finished cutting another tube from the cardboard roll, she picked up the end of Bella's tube and inserted one end of her own tube into it. At this point, she proposed to glue these pieces together (turn 01). Bella questioned, "Why?" (turn 02), and Leanne replied that she wanted a long piece (turn 03). At first, Bella suggested that the new configuration would "hit the floor" (turn 04), and then she took up the point again proposing that once it hit the floor (Figure 1c), it could not make a link to the next part that they had envisioned for their ultimate design (turn 04). Then, Leanne exhibited understanding of what "the other part" meant: she proposed to take the part that she had just produced as a chute (turn 05). Bella agreed with it, and proposed to have a board as the piece following the chute (turn 06). Leanne proposed to nail the tube to the board, then she suggested gluing the two pieces together first (turn 07).

In this situation, the two girls were engaged in developing a design of their machine. In turn, they envisioned personal design alternatives through concrete actions and thereby made them available to the others in the group. As the material configuration of their artifact was transformed (Figures 1a-1e), their vision of the ultimate outcome did not stay fixed. Whenever one envisioning action changed the 
artifact into some momentarily stable form, it gave rise to another envisioning action. For example, as soon as Bella provided a first configuration, Leanne's action came about, envisioning a long chute. In this way, the two girls articulated a vision for their machine before they stabilized it into a more fixed form through gluing or nailing. Therefore, the vision of the two girls was not just "in their heads" but distributed over their actions; the material world was not just "out there" but within the scope of designers' transforming actions.

In the collaborative design of artifacts, two or more individual subjects constitute a collective subject whose actions are oriented toward what the individuals take to be the same object, leading to the construction of one final product. A one-object-oriented activity, however, does not guarantee the same object-transforming actions by all individuals who constitute the collective subject. Rather, with each individual there may be an associated image of the object under transformation, what it ought to be transformed in, and which transformations are needed. Each personal image of the concrete materials at hand and the possibilities they constitute to action constitute a moment of subjectivity. Bella and Leanne, who designed one object to produce one (collective) outcome, constitute two persons associated with two subjectivities in the same activity. The two subjectivities were different in that each subject's perception of and action on the object unfolded in and through a separate material body of the designer as person. Differences between individual subjectivities are possible because they are associated with different material bodies. Different material bodies make possible the division of labor in that something that labor is distributed over two or more bodies. If it were not for this difference, we would not expect that collaboration could produce more than the sum of individuals.

In a dialectical approach, collaborative practice is thought in terms of the actions of individual designers, who interact to bring separate individual ideas to bear on collective motives. Collaborative practice produces and reproduces not only the design artifact as a collective object but also the artifact designers themselves as a collective (designer) subject. In the opening episode, the visions for the future shape of the collective design initially differed between the two individuals. Whereas Leanne envisioned a long chute (turn 03), Bella imagined "the other part" (turn 04), that is, a short chute. However, there was more than a discrepancy between two subjectivities. Leanne's action of connecting the two tubes at hand and turning them into a single long one provided an opportunity for Bella to articulate her vision of "the other part," and this again provided an opportunity for Leanne to vary the design by means of her brief utterance "this chute" (turn 05). Each girl accepted the other's action as part of her own next discursive or material action: the two girls acted as one designer. When Bella gestured "the other part," her action already made reference to something that she possibly had talked about to Leanne some time ago. Bella's action opened new possibilities for Leanne's next action, regardless of whether Leanne would accept Bella's suggestion or not. Leanne's next action (turn 05) not only unfolded on a common ground but also opened a new ground for any next action. This common ground against which individual actions unfold in such a communicative and cooperative fashion constitutes intersubjectivity (Roth, 2003).

Central in collaborative human practice is the dialectic of production and reproduction of intersubjectivity. To interact we require intersubjectivity; without intersubjectivity, we all would be speaking our own private language, which is a contradiction in terms (Wittgenstein, 1958). But this interaction also produces intersubjectivity; we would not need to interact if perfect intersubjectivity already existed. In Episode 1, collaborative practice unfolded through the two girls' interactions 
rather than Bella's or Leanne's individual actions or the simple sum of their actions. Working in concert, Bella and Leanne arrived at a tentative design outcome (Figure 1e). This outcome differed both from Bella's (Figure 1a) and Leanne's initial suggestions (Figure 1b). Intersubjectivity was the terrain that interactions were grounded in and the object that interactions pursued and achieved. Evaluating collaborative practice, therefore, comes down to a matter of understanding dialectical mechanisms of how interactions produce and reproduce intersubjectivity. This is a process by means of which individual actions create a new terrain of action possibilities with respect to others within a collective. It is at this point that we find a great potential inherent in collaborative practice, making people come to achieve more than the sum of what they can do individually.

The world an individual perceives and acts on is his or her everyday lifeworld; although people share the same material world, what is salient and how it is salient differs from person to person (e.g., Roth, Boutonné, McRobbie, \& Lucas, 1996) — this disjunction between material world and our consciousness of it was conceptualized in cultural historical activity theory as the double appearance of the object of consciousness (Leont'ev, 1978). In collaborative practice, different individual subjectivities of participants are made concretely available to others through actions grounded in intersubjectivity, thereby constituting a terrain of interactions and affecting action possibilities that reside at the collective level. During collaborative artifact designing, the intersubjectivity is dialectically produced and reproduced through two dominant modes of collaboration. First, face-to-face discursive and bodily communication, in which designers attend to and act on the same (part of) object, is one of the most crucial modes of producing and reproducing intersubjectivity. At this micro level interaction, human bodies take central roles in making different subjectivities available through the production, reproduction, and transformation of resources for subsequent action. Second, division of labor within an activity is a mode of collaboration in which different subjectivities attend to and act on different parts of an object. Although labor is distributed, the acting bodies make available to others intentions-even in the absence of talk-and thereby contribute to the production and reproduction of intersubjectivity. In the following two sections organized around two theoretical claims, we show that intentional actions allow the flexibility of practice to the subject and therefore give rise to successful collaboration. They do so because they producelreproduce intersubjectivity by creating "room to maneuver" for individuals, on the one hand, and by increasing "possibilities for action" for the collective, on the other. ${ }^{3}$

\section{Face-to-Face Communication: Dialectic of Resources}

Claim 1 In the mutual copresence during collaboration, each action of a human body produces and reproduces resources that are available in and to subsequent actions. Each action also concretely realizes one of many, generalized possibilities of making individual subjectivities available to coparticipants in the situation. Each action is intelligible in principle by others, thereby reproducing intersubjectivity, and contributes to the production of intersubjectivity.

3 In this study, we follow others in using a special notation for dialectical units such as production/reproduction, in which the Sheffer stroke "I" separates mutually exclusive terms within the same concept (e.g., Roth \& Lee, 2004; Roth, Tobin, Carambo, \& Dalland, 2004). Every production is a new; but it is also a form of reproduction in that it is a concrete realization of existing possibilities, and reproduction is a form of production in that it always accompanies variations in and with changing situations. Here, the form of dialectical units is consistent with the content of a dialectical unit. 
Face-to-face communication is central to collaboration. Salient at the microlevel interaction is the role of human bodies for producinglreproducing intersubjectivity. Each student's body makes a subjective understandings and intentions available in forms such as speech, gesture, or direct manipulation of materials not only to themselves but also to the generalized other; they produce resources for collective understanding. ${ }^{4}$ Different material manifestations produced by students' bodies become semiotic (meaning-making) resources for subsequent interactions and provide opportunities for variations in envisioning the collective object. A variation of materials creates new terrain of action with respect to the next action and thereby increases action possibilities (room to maneuver) at the collective level, all of which contribute to successful collaboration. The following episode, occurring when the three students (Dave, Jon, \& Maryam) communicated their designs before they arrived at their final diagram, exemplifies how one part of the design artifact (a cup of water, see Figure 3) comes to have a fixed form in their collective diagram through interactions in the mode of the face-to-face communication.

Episode 2 After Maryam, Dave, and Jon have drawn their diagrams on their individual design papers, Maryam is pointing at each part of her design and explaining it to the other two boys.

08 Maryam: Yeah like a pinball, and then it bounces, it goes through the tunnel, comes out bounces on this little rubber thing and then jumps on the panel that blows it.

09 Jon: Wouldn't it knock the over the candle, and then it starts on fire, and then [1WHOOO-

4 We follow Mikhailov (1980) in considering sounds as a production of human bodies, which allows us to eschew the over-privileging of words that characterizes much of the social sciences. As physical entities, sounds are at the same level as other bodily productions, such as positions, manipulations, sensing, and gesturing.
[ $*(($ Jon raises his arms up over his head and shakes them)) *[Figure 2a]

10 Maryam: [ ${ }_{2}$ No because-

11 Jon: $\quad\left[{ }_{2}\right.$ Here's mine, it's $\left[_{3}\right.$ not the best. $[(($ Jon picks up his design pad. $))$

12 Dave: $\quad\left[{ }_{3}\right.$ Or we can $\left[_{4}^{*}\right.$ tip it over and it'll be like a little cup ${ }_{5}$ of water. *[Figure 2b]

$\mathrm{I}_{4}$ ((Dave reaches out his left hand, hollowing the palm.))

13 Maryam: ${ }_{5}$ Yeah, a [ ${ }_{6}^{*}$ little water, yeah and then $\left[{ }_{7}^{*}\right.$ it'll tip over. *[Figure $\left.2 \mathrm{c}\right]$ $* *[$ Figure $2 \mathrm{~d}]$ $\mathrm{C}_{6}($ Ma-ryam reaches out her hands, shaping a hollow.))

${ }_{7}(($ Dave immediately turn his eyes to his diagram but Maryam continues to gesture, moving her right hand horizontally over the table with her pencil held in it.))

14 Jon: I don't have the [ ${ }_{8}$ best drawing, OK? $\mathrm{I}_{8}((\mathrm{Jon}$ put the paper that he was holding in his hand onto the table))

15 Dave: ((Dave looks at Jon's design for a while and suddenly *adds a cup of water at the right end of his diagram, which he has already finished drawing. Jon taps Dave on his arm to draw his attention to his design paper.)) *[Figure 2e]

Maryam explained her diagram to the other two boys with utterances and pointing (deictic) gestures using a pencil: a pinball would jump on the panel and blow a candle (turn 08). Once she had finished her talk, Jon responded with rather exaggerated gestures "it starts on fire" (turn 09). Maryam said "No because" and attempted to respond to Jon's comments (turn 10), but Jon's utterance "Here's mine" and his action of taking his diagram and bringing it to the conversation overlapped her utterances (turn 11). At this point, instead of attending to Jon's action, Dave made a suggestion to Maryam's design through his utterances and gestures, that of using "a little cup of water" so that the cup could tip over and put the fire out (turn 12). Even before Dave's came to utter "water," Maryam clarified it with a 


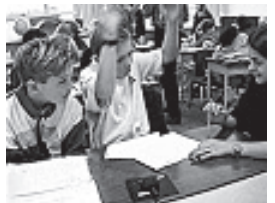

(a)

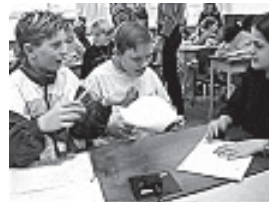

(b)

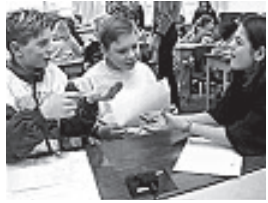

(c)

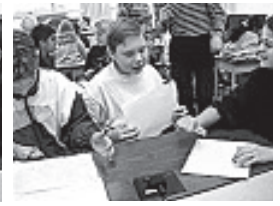

(d)

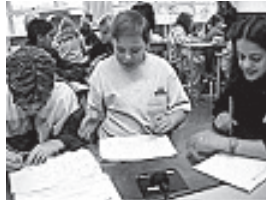

(e)

Figure 2 Dave, Jon, and Maryam is developing some initial, fleeting ideas for their design with diagrams, gestures and speech. a. Jon is shaking his hands over his head. b. Dave is hollowing the palm and gesturing a little cup of water. c. Maryam is shaping a hollow with her hands. d. Maryam is moving her right hand horizontally and gesturing the movement of ball hitting the side of cup. e. Jon finally put the paper onto the table. He is tapping Dave on the arm.

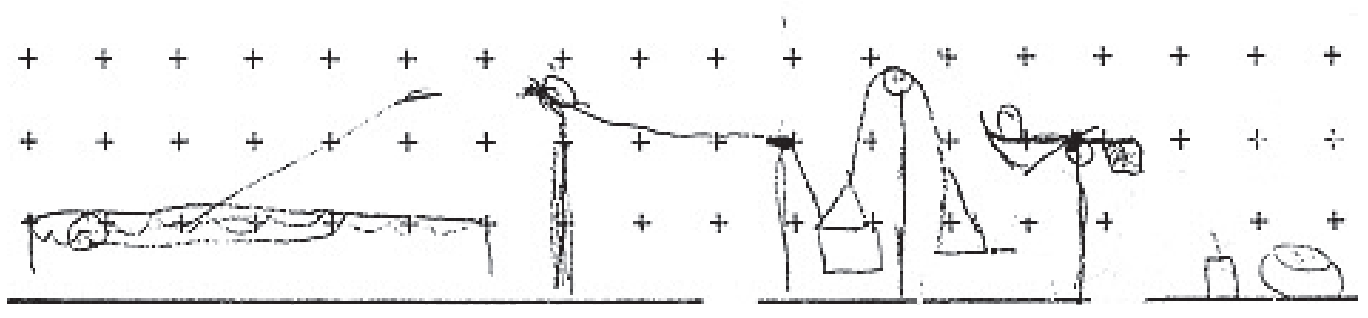

Figure 3 Dave's diagram comprises a boat, a ball on an inclined plane, a pulley, a lever, a candle, and a water pot (from left to right). This diagram becomes this group's final diagram (as per the students' choice) after a few alterations.

louder voice and gestures, "Yeah, a little water, yeah and then it will tip over" (turn 13). After Maryam gestured a hollow, Dave looked at his design pad and Jon put his design paper onto the table (turn 14). Jon paused for a while, and soon after, Dave began to draw a little cup of water on his design pad and continued it even though Jon urged him to attend to his diagram (turn 15).

In this situation, the three students concretely made their different ideas available to one another through their bodies. Maryam's speech and gestures articulated motions of a pinball, which would bounce, go through a tunnel, bounce again on a piece of rubber, and finally jump on a panel to blow a fire. Among many parts of the design that Maryam's actions articulated, the most salient one for Jon appeared to be the ending, as his responding action emphasized the risk of using a fire with uttering with louder voice "WHOOO-" and gesturing (turn 09, Figure 2a). Apparently,
Jon's action immediately drew Maryam's attention: she gazed at Jon and started to explain herself. However, Jon's concurrent action of picking up his design paper truncated further opportunities for Maryam to continue talking. At this moment and prior to Jon putting his paper on the table, Dave's hand reached over the center of the table toward Maryam and made a shape of hollow (Figure 2b). The gesture came about just as he uttered "tip it over" prior to his articulating "a little cup of water." As Dave's hands occupied the space over the table, Jon held his paper withholding further actions. At this moment, Maryam gestured a hollow toward and looked at Dave (Figure 2c), continuing the conversation with Dave about her design ideas, and once more delaying Jon's attempt to talk about his own design. Soon, Dave turned his attention from Maryam to his design paper and began to draw a cup of water on it, and Maryam turned to her own design. Finally, Jon put his diagram onto 
the table and urged the others to look at his design and listen to his ideas.

All along the episode, the three students communicated by producing something in material form such as sound, gestures, body orientations, or gaze directions. These material forms constitute resources for subsequent actions and therefore also work as semiotic resources. As the bodies produced resources that were both material and semiotic, they changed the social and material conditions of the spatiotemporal world where they were situated. The time and space in which their actions unfolded mediated what would become salient for others, but not in a deterministic way. In Episode 2, Maryam's drawing and talking provided opportunities for Jon to catch the risk of using a fire. Until Jon began to take a specific action, the possibilities in Maryam's action were unknown, that is, which particular actions could have been salient for Jon. The material configurations that Maryam produced had possibility relations to forthcoming actions. They constituted resources that Jon could include in his gestures and speech and upon which he could make variations. In producing an utterance, "WHOOO-," and a rather exaggerated gesture, Jon materialized with and through his body what was salient for him; this varied the situation as he prevented Maryam from continuing to talk and drew the attention of others to his design paper. That is, as human body materialized what was salient in the world (reproduction of resources), what it produced became resources available for next variations (production of resources).

How then does the (re-) production of resources constitute the configuration of collaborative practice? Given that resources are not just material but also have semiotic potential, a more detailed analysis of the roles of resources in the unfolding process of communication is required, particularly from a (dialectical) perspective that does not reduce collaboration to individual or collective. The immediate situation was that Maryam suggested a design drawn on her individual design paper as a candidate for embodying the collective design and Jon rejected it. At this moment, instead of directly confirming or disconfirming Jon's move, Dave suggested an alternative, comprising an utterance starting with "Or" and accompanied gestures (turn 12); if they put a cup of water, they would not have to worry about fire hazards. Dave's action changed the intersubjective terrain of the three students from a critical situation requiring a decision of whether they would accept Maryam's design or not toward a new situation creating new possibilities at the collective level. Dave's action provided an opportunity to hold on to the previously proposed design and to address the danger of fire into a new idea; Maryam's suggestion of a ball extinguishing a candle (turn 08) could become a part of their collective design while accepting generalized possibilities involved in Jon's comments.

In this situation, Dave exhibited the intention of addressing Maryam's design. Dave did not talk about it, but his body orientation and eye gaze were oriented toward Maryam. During Dave's action, Maryam was also looking at him and Jon stopped his current action. Most of all, Maryam's subsequent action, which repeated Dave's utterances and gestures, confirmed both the content of Dave's action and the intersubjectivity-the inexplicit conveyance of the three students' prior actions (Schegloff, 1996). Dave was making his subjectivity available to the others, and it could be possible because the semiotic resources that his body (re-) produced were relevant not only to him but also to the others. The concrete realization of the generalized possibilities of making different subjectivities available may return the semiotic resources back to their producers as objectified social fact (Berger \& Luckmann, 1966). In the next actions, we see how the objectified social fact could work as resources for variations. 
From Maryam's perspective, although Dave's action was directed to her own design, Dave's suggestion (a cup of water) was his personal idea. However, Dave's suggestion was not just his idea; it became an available resource to Maryam in forms of utterance and gesture. By repeating what was relevant for her, she (re-) produced the resource and made it available again to the others and to herself. Maryam's immediate action, the motion of swiping with her right hand (Figure $2 \mathrm{~d}$ ), showed that her repeating action became a resource for a variation. Throughout her actions, she transformed Dave's and her subjectivities into objective social realities, which were still subjective realities at the same time in that they constituted available resources in their lifeworlds. From Dave's perspective, Maryam's repeated action provided an opportunity for him to objectify his vision. After seeing Maryam's gesture of the hollow, Dave immediately shifted gaze to his design paper. As Jon put his paper onto the table, Dave looked at Jon's design for a while, and suddenly drew a cup of water in his own design paper. Dave's action exhibited that he was dealing with the issue of Maryam's design as part of his own design as well, therefore as an issue transcending Maryam's individual one. Dave's body produced resources relevant for Maryam's design, but the generalized possibilities inherent in those resources enabled his body again to realize those possibilities in concrete resources relevant for his own design. As Dave's action created new action possibilities, they also became possibilities at the collective level; new terrain of intersubjectivity and new room to maneuver was thereby opened up for the other two students. Maryam had opportunities to develop her design and Jon still had opportunities to show his design to others. Communication presupposes individual subjectivities and proceeds on their bases, but as the episode exemplified, it also presupposes that individual actions deal with others' subjectivities in the same terrain of their own subjectivities in the process of (re-) producing resources.

We look at the role of Jon's action in collaboration in terms of an individuallcollective dialectic. Jon's action could have been evaluated as providing room to maneuver that enabled the discussion. In fact, Jon's action provided opportunities for Dave to suggest an alternative, and Jon's subsequent "inaction" (another form of action) during Dave's action allowed room to maneuver for the other two to open a new possibility. It was revealed later on that Jon had an alternative idea for the fire part of the design, extinguishing a fire with a device including a spoon and a lever, which became an important part of their last prototype (See Figure 4). He might have wanted to show the idea to others when he was turning the topic of communication from Maryam's design to his own, which in fact was not communicated on the intersubjective terrain immediately and remained as possibilities without becoming enacted. Only Dave's subsequent action could realize one of the possibilities harbored in his action (using a fire) as the social reality.

Actions unfold in time and collaborating designers interact without exactly knowing what action would come next. Whether Jon's action contributed to successful collaboration or not, therefore, was not a matter of an individual action itself but a matter of how the new possibilities come to be apparent on the intersubjective terrain. As Dave's action enacted one of many possibilities that Jon's action potentially involved, Jon's action came to gain specific value in the collaborative practice. "Room to maneuver" is not involved in individual action itself but at the very moment in which one of the possibilities is enacted by the next action; it is located between the actions. As a relational concept, it provides an important implication 


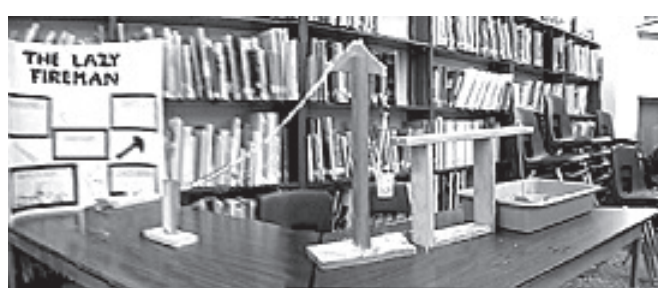

Figure 4 The final prototype of the three students' Rude Goldberg machine ("The Lazy Fireman") displayed in the school exhibition.

for the successful collaboration: an action, realizing possibilities conceived in the previous action in such a way that it raises ongoing issues to the collective level, increases room to maneuver, and leads to the successful collaboration.

After the situation in Episode 2, the three students continued to interact over and about the other two diagrams drawn in Jon's and Dave's individual papers, and finally decided to use Dave's diagram as the basis for their collective design (very similar to Figure 3). Seeing what happened as a sum of individual contributions, one might say that Maryam initiated the communication by suggesting her design and Dave ended it up as he suggested a cup of water and drew it in his diagram. Or one might say that "blowing the candle out" was Maryam's idea and "a cup of water" was Dave's idea. However, from a dialectical perspective of individual and collective, we suggest that the three students considered the possibility of using a fire, found out a problem, and straighten it out by considering a new possibility of drawing on a cup of water beside the candle. Consequently, when a cup of water became a constituting part of their final diagram, it could not be attributed to Dave's individual idea but has to be viewed as a product of collaborative practice, through which all of the three students opened up new action possibilities moment to moment and thereby increased room to maneuver to one another. Therefore, when Dave explained a diagram drawn on his individual paper, it was not his individual design but that of the three students. When the three students decided to use the diagram on Dave's paper as their collective design, they did not select simply one (Dave's) of the three diagrams, but one that belongs to the three of them.

\section{Cooperation in and Division of Labor}

Claim 2 During cooperative action, human bodies take up different parts of collective labor (achieving its division) and thereby make different contributions to an object. But the different contributions become a collective one through human bodies in action, which, in their concreteness, make available to others the sense of symbolic configurations (sounds, gestures, positions, manipulations) and intentions. The actions therefore constitute a form of communication that reproduces intersubjectivity at the same time that labor has been distributed over different subjects.

\section{Bodies as Seat of Action and Communication without Words}

Cooperation by means of a division of labor allows individual designers to differently contribute to and benefit from achieving a collective object. ${ }^{5}$ Central to dividing labor into different parts but again accomplishing them into a collective one is the role of human bodies in action. Division of labor means that individual bodies take on different tasks; but in executing tasks, the bodies and the actions they execute can be inter-

5 In a collaborating wolf pack, for example, all wolves hunt and any one may make the kill. The human hunters in Leont'ev's (1978) example divide the labor-some hunt whereas others beat the bushes and chase the game in the direction of the hunters. The beaters know that their labor is rewarded nevertheless, as contribution is made in the perspective of the subsequent food sharing. 


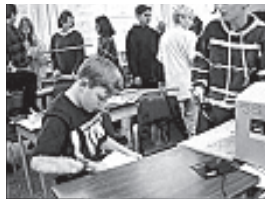

(a)

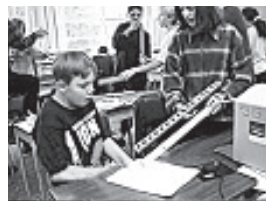

(b)

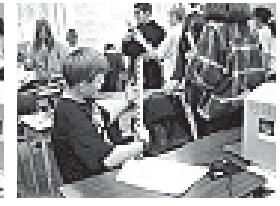

(c)

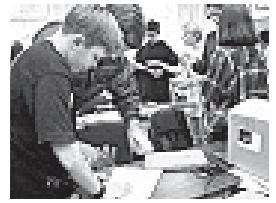

(d)

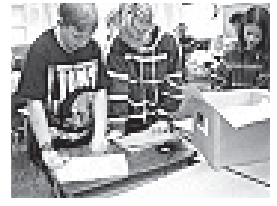

(e)

Figure 5 Dave, Jon, and Maryam are in the final stages of producing the design drawing. While Jon is getting ready for teacher's inspection of the diagram and explaining it to the teacher, the others are preparing materials for a three dimensional prototype in the classroom.

preted in terms of their intentions (Jeannerod $\&$ Pacherie, 2004). That is, different bodies simultaneously constitute the possibility of division of labor (individual subjectivities) and the production/reproduction of intersubjectivity, which arises as the main problem following corporeal division. The interaction in which an acting body engaged in one part of labor becomes available to other parts of labor, takes a feature of communication producing|reproducing individual parts on an intersubjective plane. Given that others' intentions make sense in view of the collective object, the practicability of communication implies that a communicative act is a response to that part of the distributed labor that is discriminated from one's own part.

The following episode-recorded while the three students (Dave, Jon, \& Maryam) began to render their final diagram into a three dimensional artifact - exemplify how the communicative interaction keeps on distributing artifact designing labor over the three students' different contributions but again accomplishing them into a collective. Particularly, we focus our analyses on Maryam's contribution of making a wooden stick a part of the final prototype (See a horizontal part of an inclined plane in Figure 3; a horizontal piece of wood in Figure 4) in consideration of interaction with others.
Episode 3 (11:35) ${ }^{6}$ It is the next day of discussing their diagram (Episode 2). At the beginning of the class, Jon is looking for the design paper. Dave is holding a wooden board and a hammer, and Maryam is talking to Jessica near the window, who has two sticks [Figure 5a]. (11:36) Maryam brings the two wooden sticks, one of which has regular small holes and the other does not, and says, "Hey Jon, do we need any of this?" [Figure 5b] As Jon says, "Ask Dave," Maryam calls Dave in a loud voice but Dave does not come. Jon takes one stick and looks at it [Figure 5c], but (11:37) as the teacher comes he puts the stick on the table and begins to explain the diagram to the teacher. Maryam takes the stick again and returns it to Jessica [Figure 5d]. After Maryam goes away, Dave brings the wooden board to the table and works on it with a hammer. Maryam brings one of the two wooden sticks to the table and asks Dave to pull out a nail from it. Maryam goes away with the stick, gives it to Jessica, and comes back to the table again. (11:38) As the teacher signs off on the design paper and goes away, Jon shows the diagram to Dave. Maryam is looking in the box of supplies on the other side of the table [Figure 5e].

In this situation, we see the three students take up different parts of their collective artifact designing work. Jon was sitting at the table and taking their design paper out from the drawer (Figure 5a). On the previous day, the teacher asked all students to show him a finished diagram before students could start

6 For the meso level analysis, we described episodes by the unit of minute rounding off seconds. The Episode 3 , $4, \& 5$ occurred consecutively in the same class, which began at 11:30 am and ended at $12: 10 \mathrm{pm}$, and therefore (11:35) denotes 11:35 am. 
working on a three-dimensional prototype of their design. Jon was getting his group's diagram ready for a teacher inspection. On the other side of the table, Dave was attending to a piece of wooden board while holding a hammer in his hand, and, near the window, Maryam was talking to Jessica who was holding two wooden sticks (Figure 5a). Although their design had not been approved yet, they were not sitting idly at the table. Rather, they were preparing building materials that they would use to render their design in concrete, threedimensional form. The provisional division of labor, set up in this situation, had already presupposed the intersubjectivity of the three students not only within themselves but also in relation to the teacher. Their actions implied that they did not expect there to be a problem in the approval process of their design and that Jon would be able to get approval on his own while the others were preparing materials. The three students knew their design well because they had discussed it for an extended period of time and they knew that Jon kept the design paper since their last discussion on the previous day. The division of labor had emerged as the three students started enacting what was salient and available for them in their worlds on the ground of historically (re-) produced intersubjectivity.

Intersubjectivity provides a terrain of "cooperation in division of labor" or the collective labor distributed over different individuals can be an indication of intersubjectivity. However, the reproduction of intersubjectivity is a vital condition for different parts of labor to contribute to the collective because the division of labor presupposes different bodies and therefore different individual subjectivities. The first scene exemplified that the three students were engaged in different parts of labor in accordance to their subjective visions of the collective design artifact. In subsequent scenes, we see the distributed labor over the individual students' bodies and subjectivities coming to provide opportunities of reproducing intersubjectivity, as the students interact directly and indirectly while moving back and forth between the table and other places in the classroom.

After talking for a while to Jessica near the window, Maryam brought the two pieces of wooden sticks to the table where Jon was looking at the diagram (Figure 5b). The two pieces may not have been Maryam's own materials given that she returned them to Jessica afterwards, but it is very likely that for Maryam they had been salient and available materials for the machine that she had envisioned. Maryam showed those two sticks to Jon and asked if they might be relevant materials for their machine. However, without showing any interest in them, Jon just mentioned Dave. Maryam looked up and around the classroom, calling Dave, but he did not show up. Jon took and watched one of the two sticks for a while, which had regular holes lined up (Figure 5c), but as the teacher came up to the table, he put it down on the table and became involved in explaining the diagram to the teacher (Figure 5d). Maryam did not interrupt him but let him do his part. She picked up the stick from the table and returned it to Jessica. After Maryam went away to the back of the classroom with Jessica, Dave came back to the table and began to pull out a nail on the wooden board with a hammer. Seeing Dave use a hammer to pull a nail, Maryam brought one of the two wooden sticks and asked him to pull a nail from it. Dave responded to it with his action of pulling the nail using the head of the hammer and gave the stick back to Maryam. He then looked at Jon talking to the teacher, and began to look in the box on the table.

Maryam had borrowed the two wooden sticks and attempted to communicate with the two boys about them. From her perspective, the two sticks looked like appropriate materials for the machine that they had talked about during their discussion. The two boys, 
however, did not show much interest in those materials; the two sticks did not strike them as something that would concretely realize their vision. Maryam did not insist; she had shown the sticks, thereby made them available for inspection by the two boys, and then returned them to the owner. The two boys also saw the sticks available in their worlds and did not impose what they saw on Maryam. The three students just did what was currently salient to them, but at the same time, what was salient to them could become available to others, for their acting bodies in themselves signified to others what the actions were intending in forms such as body orientation and attention to these salient entities (e.g., compare Figure $5 b$ \& c). That is, individual acting bodies constitute not only the division of labor but also a configuration of communication. The materials, salient on an individual plane, thereby become salient at an intersubjective plane even when the participants do not talk-scientists have been reported to go for long stretches of laboratory work without exchanging a word and yet know that others know and are attuned to the events (Roth, 2004).

This kind of social interaction, which does not accompany an immediate response to or a variation of others' actions, may look much weaker and therefore less important than verbal exchanges. However, indirect communication-knowing that others know and attend to the same thing I am attending to, which therefore goes without saying - is a dominant form of interaction among scientists (Roth, 2004b). It was also the case among the students in the present study, who were working on different parts of a collective object ("cooperation in division of labor"). We can find more examples of indirect communication in Dave's action of looking at Jon talking to the teacher and then going back to his work, or Maryam's action of looking at materials in the box while seeing the two boys talking about the diagram (Figure 5e). While distributing the collective labor over their different bodies, they were reproducing intersubjectivity by seeing what others were doing and by hearing what others were saying.

\section{Production I Reproduction of Intersubjectivity Redistributes the Division of Labor}

Given that every communicative act constitutes a response to the collective object, the interaction, taking a feature of communication, develops the collective object (design artifact) through the collective labor distributed|redistri buted over acting individual bodies. Therefore, the value of a material such as a diagram, a wooden stick, or a wooden board was not in its presence itself but lied in the fact that a designer was acting on it through his or her body. In Episode 3, Maryam had borrowed two wooden sticks with a vision of considering them as plausible candidate materials for the collective design artifact. Maryam's actions on the stick remained just in her part of labor without being re-distributed over the other parts of labor. In consequence, Maryam turned her attention to several different materials instead of the sticks while keeping in communication with others, but no material had become a collective object. In the following episode (Episode 4), one wooden stick finally came to be the collective object salient to all the three students.

Episode 4 (11:43) Maryam walks up and talks to Jessica again, who still has the two long sticks in her hands. Maryam holds the stick that does not have holes on it. Dave and Jon come up to and join Maryam and Jessica [Figure 6a]. (11:44) Jon takes the stick from Maryam and moves to the table [Figure 6b]. He calls Dave. Dave and Maryam move to the table. Jessica gives the other stick to Dave. He takes it and looks at it carefully [Figure 6c]. Soon, Jessica talks something, and Maryam returns the stick that Dave was holding to Jessica. (11:45) Jon and Dave look at the other remaining stick. They open the toolbox and take a screwdriver out. Dave tries to take down a small piece of wood attached to the main stick with the screwdriver. Jon 


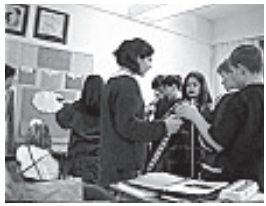

(a)

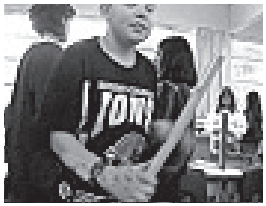

(b)

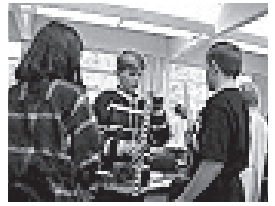

(c)

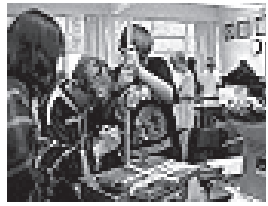

(d)

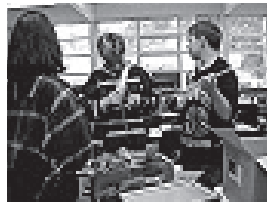

(e)

Figure 6 The three students are taking a wood stick from their classmate and removing a small piece of wood so that it is to be the right materials for concretely realizing the artifact in three-dimensional material form.

holds the main piece of wood vertically. Dave puts the screwdriver in a crack and presses it. Maryam comes back to the table from Jessica and asks the two boys, "Which one do you guys want?" [Figure 6d]. Jon says "this one." (11:46) Maryam sees the screwdriver not working successfully to remove the small piece of wood. She suggests using a saw [Figure 6e].

After scouring the classroom for relevant and available materials for the collective design artifact — sometimes by herself and sometimes with others-Maryam returned to Jessica, from whom Maryam had borrowed the two wooden sticks before (See Episode 3). Dave and Jon, who had returned to the table and looked around the classroom, saw Maryam talking to Jessica holding one stick in her hand and they then approached the two girls (Figure 6a). The two boys' actions contrasted the previous instances in which Maryam had brought the two sticks and shown them to the two boys who were sitting at the table. After a brief conversation, Jon took one stick from Maryam and brought it to the table (Figure 6b). He urged Dave and Maryam to join him. Jessica handed the other stick to Dave who was about to come back to the table. Dave took it and looked at it carefully (Figure 6c), but it was returned to Jessica following her request. The two boys looked in the box, pulled some tools from it, and began to remove a small piece of wood attached to the main stick with a screwdriver and a hammer (Figure 6d).

In this situation, Maryam's action on the two sticks may not look different from her action in Episode 3 (Compare Figure 5c \& 7a), but it made a difference because of the subsequent actions of the two boys (Figure 6a-e) and the inter-actions between the three students. The boys went to Maryam, took the stick held in her hand, and began to consider its shape. Their actions implied that Maryam's action was interpreted in terms of an intention to use the sticks for the machine within the subjective worlds of the two boys. Through the communicative interaction, the two boys responded to Maryam's action in view of the collective object, and thereby realized the stick as a constituting part of their collective design artifact. As the two boys joined Maryam's work (action on the sticks) and began to work on one stick, Maryam's part of labor was distributed over the two boys' action and the collective labor was redistributed in forms of a newly set up division of labor. We understand this distribution in the spirit of dialectical continuity. Maryam's part of labor may look like having moved into the two boys' part as the stick moved from Maryam's hand to the two boys' hands. However, the change occurred because of the three students' engaged action, which we prefer understanding as a process of "distribution-interfering interaction-redistribution" following the quantum mechanical descriptions of waves.

Seeing the two boys working on the stick, Maryam went to Jessica in another table instead of joining the two boys. After a while, she rejoined the two boys and asked if the current stick was what they wanted to use (Figure 6d). Her question indicated that if 
the two boys thought the other stick was better, she would be able to make it available. Maryam's action showed that she took a new part of contribution, which was necessary but cannot be done by the two boys currently engaged in cutting a wooden piece. As Jon gave a positive reply about the current stick, Maryam suggested using a saw (Figure 6e) and began to look for the next materials to be used. Maryam had been providing the two boys with opportunities to contribute to the activity in different ways from her when she scoured the classroom for materials while Jon was explaining the diagram to the teacher or while Dave was sitting at the table and elaborating the diagram. By engaging in different parts of contribution to increasing possibilities for achieving the collective object, her actions created room to maneuver with respect to the others. If we do not consider the activity as a whole, it may look like that the two boys worked hard on the machine and Maryam just wandered around the classroom talking to her friend. However, the sequence of Maryam's action indicated that through her every action she pursued the collective object while attending to others' part of labor, which articulated itself in and as of the flexible division of labor. In all instances, human bodies took a central role to facilitate collaboration through their communicative act-e.g., like seeing what others were doing and knowing that others know they are seeing it.

\section{Dialectics in and of Collaboration}

\section{Semiotic Value and Use Value}

We began our study with the question, "How do different people collaborate and come to achieve more than the sum of what they can do individually?" In articulating our answer to this question, we arrived at specifying a mechanism of how interactions produce and reproduce intersubjectivity, and in response, we analyzed two dominant configurations of collaborative practice from a dialectical perspective of an individuallcollective unit. The central role of the human body in both bringing about differences (in labor, subjectivity) and affording intersubjectivity is salient in our analyses. Our approach is different from many others in that we do not privilege sound objects (words, language), but consider all structure available in and made available by participants in some situation as potential resources of communication (e.g., Roth, 2004a). We therefore showed that at the micro level interaction of face-to-face communication, the dialectal variation of resources constitutes a mechanism of producing|reproducing intersubjectivity and at the meso level interaction of cooperation in division of labor, the distrib ution|redistribution of collective labor through communication turns out as a configuration of producing|reproducing intersubjectivity. Of significance to those configurations of collaborative practice is the role of "human body."

How to theorize human collaborative practice has been an essential task of social research inquiring the human practice and development. We argue that theorizing human body as a dialectical unit of collaborative practice can open a new horizon to understand the value of collaboration without dichotomizing its productive and communicative aspects. In collaborative practice, human body constitutes a dialectical unit that harbors a contradiction between semiotic value and material valuewhich we see as analogous to Marx's concept of contradiction between (exchange) value and use value (Il'enkov, 1982). The foundation of such a contradiction is the internal necessity for the different two moments to constitute one indivisible body independent of them. They are two extremes being exclusive and opposing each other. The value is the materialization of the social nature of human labor. Despite of its materialization, it is a social material being and 
therefore it cannot exist as a simple property of a commodity. Semiotic value and material value are mutually constitutive because conceptualization of one presupposes the other. However, they are mutually exclusive for they do not appear at the same time in temporally unfolding actions (reality).

Throughout our episode analyses, we showed that may it be verbal or non-verbal the act of the material body made one's subjectivity available to the other and thereby achieved itself as semiotic resources. At the very moment, however, that one's act was comprehensible not only to the other but also to oneself, the acting body had already constituted material resources for the next action that made variations in and of a collective object. This materiality of acting bodies opened up possibilities for communicative acts to transcend the individual and thereby to become a productive act toward a collective object. That is, in the materiality of their actions, human bodies concretely realize their semiotic value, which inevitably constrains and affords communication, thereby achieving the configuration of collaboration.

Collaborators, whether engaged in the same labor or different parts of distributed labor, configure a unique constellation of interaction, where their actions not only get things done in the material world but also overcome the distance between different subjectivities. The actions not only create opportunities for new semiotic value to emerge concerning the collective object, but also presuppose the existence of the object as a collective one. Grounded in acting human bodies, the new meanings articulate themselves in and as "room to maneuver" (action possibilities) that acting bodies create with respect to concurrent and forthcoming actions. We understand this as the (metaphorical) space where people act, learn, and develop through social interactions.

\section{Extensions}

Our dialectical framework of collaboration centered on human body has many significant implications for research on human practice and learning. Among them, we provide two main suggestions concerning the concept of object and intersubjectivity, which focus on the productive and communicative aspect of human collaboration respectively. First, there have been a wide range of approaches to the social construction and transformation of object to understand the social dimension of scientific practice (Sismondo, 1993). Particularly, activity theorists have developed the concept of object into including not only materials and tools but also human vision and knowledge (e.g., Miettinen, 1998). Those approaches have made tremendous contributions to overcoming the dichotomy between subject and object and theorizing the structure of practice, in which concurrent subjectification and objectification processes occur (Nissen, 2003). However, in return for gaining a rich picture of object and associated systemic changes, the systemic view became blind to the grounds of actions that real human beings use in practice (e.g. Holzkamp, 1991). We argue that a dialectical perspective of human practice necessarily comes to extend the concept of object to human bodies that constitute and produce resources of collaborative practice - the presence of a material or a representation itself is not enough to understand how the collaborative practice unfolds.

Second, intersubjectivity is a long-standing concept in scholarly effort to articulate the relation between self and other, of which the central social phenomenon is communication. As many studies in diverse settings have reported, people communicate not only through discursive interaction but also through bodily interaction such as gestures, body orientations, or pitch changes (e.g., McNeill, 2002). The notion of intersubjectivity rooted in human body has been already emphasized in phenomenological social theories (e.g., Merleau-Ponty, 1958), but 
less attention was given to how human bodies producelreproduce intersubjectivity through communicative social interaction. In many domains, researchers have little appreciation of the productive aspect of communication, which can transcend just "pro-and-con" talk. We argue that the dialectical approach to communication needs to move from a focus on intersubjectivity to the production/reproduction of intersubjectivity. This means asking, for example, "How do our differences make us the same and how does our sameness make us different?" rather than asking, "How much are we the same?" or "By how much do we differ?" Changing focus necessarily requires placing acting human bodies at the center of intersubjectivity because our actions simultaneously make us the same (i.e., intersubjectivity) and different (i.e., subjectivities). Our dialectical framework also opens up possibilities to understand intersubjectivity without dichotomizing cognition and emotion. Our acting bodies constitute both seat and carrier of all what we know and feel, and therefore producing|reproducing intersubjectivity is simultaneously cognitive and emotional phenomena (Roth, in press). For example, feeling positive emotion toward others leads people to deal with others' work as part of their own work and thereby produce and reproduce intersubjectivity even without conscious effort to collectivity.

\section{Coda}

Collaboration is a practice of which productive material value is achieved through communicative act of human bodies and at the same time, its communicative value is achieved through materiality of acting human bodies. The value of collaboration, which makes collaboration more than the sum of individual actions, does not lie in individual actions themselves, but in the "room" that they create for future actions. That is, to theorize collaboration we need an understanding of the material resources produced and reproduced by human bodies dur- ing the unfolding of communicative actions; we also need an understanding of the semiotic resources that human bodies produce and reproduce during unfolding cooperative actions. To fulfill the two requirements, we have to read between the actions (in the way we read between the lines). Such reading transcends reading between lines in that actions are always concrete modes of acting human bodies extending beyond the words-actions speak louder than words.

\section{Acknowledgments}

This work was supported by a grant from the Social Sciences and Humanities Research Council of Canada, and by a postdoctoral fellowship from the Korea Science and Engineering Foundation. We are thankful for Sylvie Boutonné, Michelle K. McGinn, and Carolyn Woszczyna, who assisted us in the establishing the database. Michael Hoffmann's incisive critique incited us to refine our own understanding that allowed us to develop these new explanations of collaboration. We are also grateful to the Victoria CHAT@UVic group (Diego Ardenghi, Leanna Boyer, Yew Jin Lee, and Giuliano dos Reis) for providing a forum for discussion of our ideas.

\section{References}

Berger, P., \& Luckmann, T. (1966). The social construction of reality: A treatise in the sociology of knowledge. New York: Doubleday \& Company, Inc.

Brown, A. L. (1992). Design experiments: Theoretical and methodological challenges in creating complex interventions in classroom setting. Journal of the Learning Sciences, 2, 141-178.

Engeström, Y.(1987). Learning by expanding:An activity-theoretical approach to developmental research. Helsinki: Orienta-Konsultit.

Gallagher, S. (2004). Phenomenological and experiemental contributions to understanding embodied experience. In T. Ziemke, J. 
Zlatev, R. Frank \& R. Dirven (Eds.), Body, language and mind (pp. ••••••). Berlin: Walter De Gruyter.

Heath, C., \& Hindmarsh, J. (2000). Configuring action in objects: From mutual space to media space. Mind, Culture, and Activity, 7, 81-104.

Holzkamp, K. (1983). Grundlegung der Psychologie. Frankfurt: Campus.

Holzkamp, K. (1991). Experience of self and scientific objectivity. In C. W. Tolman \& W. Maiers (Eds.), Critical psychology: Contributions to an historical science of the subject (pp. 65-80). Cambridge: Cambridge University Press.

Hyysalo, S. (2002). Transforming the object in product design. Outlines, 1, 59-83.

Il'enkov, E. (1982). Dialectical of the abstract and concrete in Marx's Capital (Translated by S. Kuzyakov). Moscow: Progress. (Original work pulished 1960)

Jeannerod, M., \& Pacherie, E. (2004). Agency, simulations and self-identification. Mind \& Language, 19, 113-146.

Jordan, B., \& Henderson, A. (1995). Interaction analysis: Foundations and practice. The Journal of the Learning Sciences, 4, 39-103.

Lektorsky, V. A. (1999). Historical change of the notion of activity: Philosophical presuppositions. In S. Chaiklin, M. Hedegaard, \& U.J. Jensen (Eds.), Activity theory and social practice (pp. 100-113). Aarhus: Aarhus University Press.

Leont'ev, A. N. (1978). Activity, consciousness and personality. Englewood Cliffs, CA: Prentice Hall.

Leont'ev, A. N. (1981). Problems of the development of the mind. Moscow: Progress Publishers.

McNeill, D. (2002). Gesture and language dialectic. Paper presented at the conference The Multimodality of Human Communication: Theories, Problems, and Applications, Toronto, Canada, May 3-5.
Merleau-Ponty, M. (1958). Phenomenology of perception (Translated by C. Smith). London: Routledge.

Miettinen, R. (1998). Object construction and network in research work: the case of research on cellulose-degrading enzymes. Social Studies of Science, 28, 423-463.

Mikhailov, F. (1980). The riddle of self. Moscow: Progress. (Original work published 1976).

Nissen, M. (2003). Objective subjectification: The antimethod of scial work. Mind, Culture, and Activity, 10, 332-349.

Roth, W.-M. (2003). From environmental determination to cultural-historical mediation: toward biologically plausible social theories. Cybernetics And Human Knowing, 10(2), 8-28.

Roth, W.-M. (2004a). Communication as situated, embodied practice. In T. Ziemke, J. Zlatev, R. Frank \& R. Dirven (Eds.), Body, language and mind (pp. ••••••). Berlin: Walter De Gruyter.

Roth, W.-M. (2004b). Perceptual gestalts in workplace communication. Journal of Pragmatics, 36(6), 1037-1069.

Roth, W.-M. (in press). What does a teacher need to know about cognition? In J. Kincheloe (Ed.), 19 questions about classroom teaching (pp. •••-•••). New York: Peter Lang.

Roth, W.-M., Boutonné, S., McRobbie, C. J., \& Lucas, K. B. (1996). One class, many worlds. International Journal of Science Education, 21, 59-75.

Roth, W.-M., \& Lee, Y. J. (2004). Interpreting unfamiliar graphs: A generative, activitytheoretic model. Educational Studies in Mathematics, 57, 265-290.

Roth, W.-M., Tobin, K., Carambo, C., \& Dalland, C. (2005). Coordination in coteaching: Producing alignment in real time. Sci-

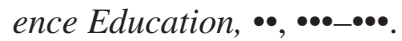

Schegloff, E. A. (1996). Confirming allusions: Toward an empirical account of ac- 
tion. American Journal of Sociology, 102, 161-216.

Sismondo, S. (1993). Some social constructions. Social Studies of Science, 23, 515-53.

Sten Have, P. (1999). Doing conversation analysis: A practical guide. London: Sage Publication.
Vygotsky, L. S. (1978). Mind in society: The development of higher pyschological processes. Cambridge, MA: Havard University Press.

Wittgenstein, L. (1958). Philosophical investigations (3rd ed.). New York: Macmillan. 